\title{
A enfermeira diplomada e a luta contra tuberculose no Brasil: 1961-1966*
}

\section{Hercília Regina do Amaral Montenegro', Antonio José de Almeida Filho², Tânia Cristina Franco Santos ${ }^{3}$, Lucia Helena Silva Corrêa Lourenço ${ }^{4}$}

\section{RESUMO}

O objeto desse estudo é a reconfiguração do Serviço de Enfermagem do Hospital Estadual Santa Maria, frente a uma nova política contra a tuberculose no Brasil. Objetivos: descrever as circunstâncias que ensejaram a implantação do novo Programa de Ação na Luta contra a Tuberculose no Brasil, e discutir as estratégias utilizadas pelas enfermeiras diplomadas do Hospital Estadual Santa Maria, no Estado da Guanabara, para adequar a assistência de enfermagem ao novo programa de combate à tuberculose. Estudo histórico-social. Para sua elaboração, foi realizada pesquisa documental, entrevistas e depoimentos de enfermeiras da época. A análise do corpus documental, apoiada pelos conceitos de habitus, campo e poder simbólico de Pierre Bourdieu, se fez com base em documentos escritos, orais e fontes secundárias. Resultados: a reconfiguração do serviço de enfermagem se deu sob a liderança de uma enfermeira cujo capital simbólico lhe conferia poder e prestígio para implementar as mudanças necessárias. Pode-se concluir que a atuação dessa enfermeira possibilitou a implantação do novo programa, e contribuiu para demarcar o espaço e a importância da enfermeira diplomada na assistência aos acometidos de tuberculose, tanto nos aspectos de prevenção quanto nos de cura.

\section{DESCRITORES}

História da enfermagem. Tuberculose pulmonar.

Liderança.

\section{ABSTRACT}

The objective of this study was to describe the circumstances that promoted the implementation of the new Program for Action Against Tuberculosis in Brazil (Programa de Ação na Luta contra a Tuberculose no Brasil) and discuss the strategies used by registered nurses from the Santa Maria State Hospital, Guanabara State, to adjust nursing care to the new program against tuberculosis. This was performed through document research, interviews, and statements from nurses working at the time of the reorganization. Documents were analyzed based on the concepts of habitus, field, and symbolic power by Pierre Bourdieu, and included written and oral documents as well as secondary sources. The reorganization of the nursing service was performed under the leadership of a nurse whose symbolic capital assigned power and prestige to implement the necessary changes. It is concluded that the work of that nurse made it possible to implement the new program and contributed to establishing the position and importance of the registered nurse in providing care to individuals with tuberculosis, for prevention and cure.

\section{KEY WORDS}

History of nursing.

Tuberculosis, pulmonary. Leadership.

\section{RESUMEN}

El objeto de este estudio fue la reconfiguración del Servicio de Enfermería del Hospital Estatal Santa Maria, frente a una nueva política contra la tuberculosis en Brasil. Objetivos: describir las circunstancias que permitieron la implantación del nuevo Programa de Acción en la Lucha contra la Tuberculosis en Brasil, y discutir las estrategias utilizadas por las enfermeras diplomadas del Hospital Estatal Santa Maria, en el Estado de la Guanabara, para adecuar la asistencia de enfermería al nuevo programa de combate a la tuberculosis. Estudio histórico social. Para su elaboración, fueron realizadas una investigación documental y entrevistas/declaraciones de enfermeras de la época. El análisis del corpus documental, apoyado por los conceptos de habitus, campo y poder simbólico de Pierre Bourdieu, se hizo con base en documentos escritos, orales y fuentes secundarias. Resultados: la reconfiguración del servicio de enfermería sucedió bajo el liderazgo de una enfermera cuyo capital simbólico le confería poder y prestigio para implementar los cambios necesarios. Se puede concluir que la actuación de esa enfermera posibilitó la implantación del nuevo programa, y contribuyó para delimitar el espacio y la importancia de la enfermera diplomada en la asistencia a los acometidos de tuberculosis, tanto en los aspectos de prevención como en los de cura.

\section{DESCRIPTORES}

Historia de la enfermería. Tuberculosis pulmonar. Liderazgo.

\footnotetext{
* Extraído da dissertação "A nova ordem social na luta contra a tuberculose e a reconfiguração da assistência de Enfermagem do Hospital Estadual Santa Maria", Escola de Enfermagem Anna Nery, Universidade Federal do Rio de Janeiro, 2007. ${ }^{1}$ Mestre em Enfermagem. Coordenadora do Serviço de Educação Continuada do Hospital Geral de Jacarepaguá. Supervisora de Enfermagem do Hospital Estadual Santa Maria. Primeira Secretária ABEn-RJ. Rio de Janeiro, RJ, Brasil. herciliaregina@oi.com.br ${ }^{2}$ Doutor em Enfermagem. Pesquisador do Núcleo de Pesquisa de História da Enfermagem Brasileira (Nuphebras). Membro do Corpo Docente Permanente do Programa de Pós-Graduação e Professor Adjunto do Departamento de Enfermagem Fundamental da Escola de Enfermagem Anna Nery, Universidade Federal do Rio de Janeiro. Rio de Janeiro, RJ, Brasil. ajafilho@terra.com.br ${ }^{3}$ Doutora em Enfermagem. Pesquisadora e membro da Diretoria Colegiada Nuphebras. Membro do Corpo Docente Permanente do Programa de Pós-graduação e Professora Adjunta do Departamento de Enfermagem Fundamental da Escola de Enfermagem Anna Nery, Universidade Federal do Rio de Janeiro. Rio de Janeiro, RJ, Brasil. taniacristinafsc@terra.com.br ${ }^{4}$ Doutora em Enfermagem. Pesquisadora e membro da Diretoria Colegiada do Nuphebras. Membro do Corpo Docente Permanente do Programa de Pós-graduação e Professora Adjunta do Departamento de Enfermagem Fundamental da Escola de Enfermagem Anna Nery, Universidade Federal do Rio de Janeiro. Rio de Janeiro, RJ, Brasil. helenalourenco@uol.com.br
} 


\section{INTRODUÇÃO}

O estudo tem como objeto a reconfiguração do Serviço de Enfermagem do Hospital Estadual Santa Maria (HESM), situado no antigo Estado da Guanabara, diante de um novo Programa de Ação na Luta contra a Tuberculose no Brasil. 0 recorte temporal compreende os anos de 1961 a 1966, sendo o marco inicial justificado pela definição de uma nova política de combate à tuberculose, no bojo da Campanha Nacional contra a Tuberculose (CNCT), e distinta da existente até aquele momento. $\mathrm{O}$ marco final refere-se ao período da gestão de uma enfermeira, como chefe do Serviço de Enfermagem no HESM, com a função de liderar a implantação das mudanças necessárias naquele serviço, de modo a atender a nova proposta de assistência aos doentes portadores de tuberculose pulmonar no Estado da Guanabara. 0 êxito dessa nova política de combate à tuberculose consolidaria uma nova fase no tratamento à tuberculose no Brasil.

Desde a década de 1940, estudos epidemiológicos já evidenciavam a gravidade da tuberculose e o seu impacto na sociedade brasileira, em face às altas taxas de morbidade e mortalidade. Estudos demonstravam que algumas capitais brasileiras atingiam a marca de 300 a 500 óbitos por 100.000 habitantes, e no Rio de Janeiro, então Capital Federal, o índice era de aproximadamente 320 por 100.000 habitantes $^{(1)}$. Entre 19 capitais estaduais, 12 mantiveram-se com índices crescentes de tuberculose pulmonar entre os anos de 1936 a 1945. Essa situação era tão grave que a constituição da Força Expedicionária Brasileira (FEB), criada para atuar junto aos aliados na Segunda Guerra Mundial, teve a tuberculose pulmonar como o principal motivo para o reduzido desempenho físico dos militares e pelas baixas antecipadas dos mesmos naquele conflito ${ }^{(2)}$.

Diante da vulnerabilidade da população à doença, que era agravada pelas condições de vida e de trabalho de operários mal remunerados, pela excessiva jornada de trabalho, alimentação inadequada e condições insalubres de moradia(3), o governo Eurico Gaspar Dutra (1946-1951), ao elaborar o Plano SALTE (Saúde, Alimentação, Transporte e Energia), no que competia à saúde, estabeleceu como ponto prioritário o combate à tuberculose. Tanto assim que o presidente Dutra, durante a fase de elaboração da nova Constituição, sancionou o Decreto-lei $n$ o 9387 que institui oficialmente a Campanha Nacional contra a Tuberculose - $\mathrm{CNCT}^{(3)}$, nomeando o médico Raphael de Paula Souza para a direção do Serviço Nacional de Tuberculose e para a Superintendência da CNCT.

Na década de 1950, mais precisamente a partir de 1956, pesquisadores nacionais e internacionais demonstraram que o tratamento não hospitalizado era viável, independentemente da gravidade das lesões e das condições socioeconômicas do doente, não sendo necessário o seu afastamento das atividades laborais. As pesquisas indicavam que o uso regular dos medicamentos combinados, no tempo correto, assegurava a cura. Diante desse novo paradigma, houve um redirecionamento nas ações da CNCT, com a reorganização dos dispensários e implantação de novos serviços, incluindo a contratação, preparo e treinamento de pessoal. Até aquele momento, o tratamento sanatorial era caracterizado pelo incentivo à criação de leitos hospitalares ${ }^{(4)}$, o que aumentava significativamente o custo do tratamento.

Não obstante, constatava-se, na década de 1950, que, se por um lado ocorria um declínio nas taxas de mortalidade da tuberculose, por outro se tinha o desenvolvimento de resistência bacteriana a uma ou mais drogas devido ao uso inadequado de antibióticos. Também nesse período, as autoridades de saúde já tinham conhecimento de que o tratamento adequado da tuberculose tornava as fontes de contágio negativas num período de três a quatro meses após o início do tratamento, e que curava $90 \%$ dos casos, independente do tipo de lesão ${ }^{(5)}$. Com isso, as instituições de saúde tiveram grande importância tanto na implementação de medidas profiláticas como no tratamento. Essas medidas contemplavam: vacinação; detecção precoce de novos casos; e educação sanitária, que consistia em orientações aos doentes quanto ao contágio e ao tratamento da tuberculose e enfatizava o uso correto dos medicamentos ${ }^{(6)}$.

No que concerne à enfermagem, as novas tendências para o tratamento da tuberculose demandavam a necessidade de profissionais qualificados e atualizados para dar conta da assistência aos doentes nas diversas instituições de saúde. De modo a atender tais necessidades, foi realizado, no início da década de 1960, um estudo por uma Comissão Supervisora de Enfermagem no Estado da Guanabara, intitulado Levantamento das Necessidades de Enfermagem no Estado da Guanabara, que contou com a participação de chefes de enfermagem de todas as unidades hospitalares do Estado. Esse estudo, que visava identificar a legitimidade dos profissionais de enfermagem das unidades hospitalares do Estado, revelou que

havia uma expressiva quantidade de profissionais sem a titulação requerida para prestar assistência aos pacientes hospitalizados, sendo alguns admitidos através de critérios eleitorais ou políticos ${ }^{(7)}$.

O fato constatado contrariava a legislação vigente para o exercício profissional na enfermagem e comprometia a qualidade da assistência de enfermagem desenvolvida naquelas instituições. Alguns profissionais que não possuíam o diploma de enfermeiro eram denominados enfermeira(o)s titulada(o)s e assumiam, em alguns casos, a função de chefe do Serviço de Enfermagem.

Pôde-se constatar que tanto as enfermeiras tituladas quanto os auxiliares de enfermagem apresentavam baixo 
nível de escolaridade. Além disso, ainda era comum, sobretudo nos hospitais, permitir, sem seleção prévia, a presença de estagiários, considerados as pessoas com baixo nível de instrução, a maioria apenas alfabetizada, que prestava serviços sem remuneração com vista à nomeação para os cargos de atendentes de enfermagem. Havia os albergados, assim denominados aqueles que recebiam trimestralmente uma pequena remuneração, além de moradia em alojamento coletivo, alimentação e uniforme, e, ainda, os gandulas, ex-pacientes de doenças crônicas como hanseníase ou tuberculose ou doentes em fase de recuperação que moravam no hospital e dele recebiam uniforme e alimentação em troca do seu serviço(7).

A precária formação profissional daqueles que prestavam assistência de enfermagem no âmbito da Secretária de Saúde e Assistência do Estado da Guanabara refletia-se na qualidade da assistência prestada aos pacientes hospitalizados. Essa conjuntura que se perpetuou ao longo dos anos também ocorria no HESM. Assim, diante dos novos rumos no controle da tuberculose, advindos da evolução da quimioterapia e da valorização do tratamento dispensarial, houve a necessidade de adequação a essas demandas, de modo a prevenir as possíveis resistências às drogas.

Nesse contexto, em 1963, o assessor técnico Dr. José Galbo (médico tisiologista, ex-diretor do Departamento de Tuberculose do Estado da Guanabara e ex-diretor do Hospital São Sebastião) foi nomeado substituto eventual do diretor do HESM. Ao tomar posse do referido cargo, convidou a enfermeira Raimunda da Silva Becker para chefiar o Serviço de Enfermagem. Vale ressaltar que Raimunda da Silva Becker fora chefe do Serviço de Enfermagem do Hospital São Sebastião em sua gestão como diretora do hospital. Portanto, coube à enfermeira Raimunda da Silva Becker, nomeada para o cargo em 19 de fevereiro de 1964, a adequação do Serviço de Enfermagem às novas demandas do combate à tuberculose.

Diante do exposto, para esse estudo foram traçados os seguintes objetivos: descrever as circunstâncias que ensejaram a implantação do novo Programa de Ação na Luta contra a Tuberculose; e discutir as estratégias utilizadas pelas enfermeiras diplomadas do HESM para adequar a assistência de enfermagem ao novo programa de combate à tuberculose.

\section{MÉTODO}

Este estudo é histórico-social, pois reflete posições diante da realidade, momentos do desenvolvimento e da dinâmica social, e preocupações e interesses de classes e de grupos determinados ${ }^{(8)}$. É derivado da Dissertação de Mestrado intitulada $A$ nova ordem social na luta contra a tuberculose e a reconfiguração da assistência de Enfermagem do Hospital Estadual Santa Maria, cujo projeto foi aprovado pelo Comitê de Ética em Pesquisa da Escola de Enfermagem Anna Nery/Hospital Escola São Francisco de
Assis, em 19 de dezembro de 2006, conforme parecer número 097/06.

As fontes primárias estão constituídas de documentos escritos e documentos orais pertencentes ao Acervo de História Oral do Centro de Documentação (CEDOC) da Escola de Enfermagem Anna Nery (EEAN)/UFRJ e da Biblioteca da ENSP/FIOCRUZ. Também foram realizadas entrevistas com a professora Raimunda da Silva Becker e com a enfermeira Antonia de Oliveira Coelho, no Pavilhão de Aulas da Escola de Enfermagem Anna Nery e na residência da própria depoente, respectivamente. Além disso, foi obtido o depoimento escrito da enfermeira Jurema Cunha dos Santos. Em ambos os casos, foram tomadas as precauções éticas no que concerne ao consentimento livre e esclarecido, em cumprimento da Resolução 196/96 do Conselho Nacional de Saúde.

Os fragmentos dos depoimentos, quando apresentados no texto, serão identificados com as iniciais do nome da depoente correspondente, como se segue: enfermeira Raimunda da Silva Becker (RSB), enfermeira Antonia de Oliveira Coelho (AOC) e enfermeira Jurema Cunha dos Santos (JCS).

Nos estudos históricos, é importante situar o sujeito no contexto histórico-social em que o tal fenômeno aconteceu, inclusive considerando a função exercida, o cargo ocupado, entre outros. Assim, todos os depoentes estavam cientes da impossibilidade de manutenção do anonimato e concordaram com esse procedimento. É relevante registrar que os depoentes cederam seus depoimentos ao CEDOC da EEAN/UFRJ, de modo que pudessem ser consultados por outros pesquisadores, para fins de trabalhos científicos.

As fontes secundárias relativas à temática do estudo foram localizadas na Biblioteca Setorial da Escola de Enfermagem Anna Nery, Biblioteca da Fundação Getúlio Vargas e Biblioteca da ENSP/ FIOCRUZ.

Tanto os documentos escritos como as transcrições das entrevistas foram utilizadas como textos a serem interpretados, inseridos no contexto histórico em que foram produzidos. A análise dos dados teve como referência teórica os conceitos de campo, habitus e poder simbólico do sociólogo francês Pierre Bourdieu.

A questão fundamental dos escritos de Bourdieu é o entendimento do caráter estruturado das práticas sociais, em que cada sujeito, em função de sua posição nas diversas estruturas sociais, vivencia uma série característica de experiências que estruturam internamente sua subjetividade e orienta suas ações em ações subsequentes. A atuação de Raimunda da Silva Becker como chefe do Serviço de Enfermagem do HESM, nas questões concernentes ao combate à tuberculose, evidenciou a incorporação de um capital específico, mediante atualização de seu habitus, em resposta às lutas simbólicas pelo poder de se fazer ver e de se fazer crer e se dar a conhecer, pois, em meio à luta pela imposição de uma visão de mundo legítima, os agentes 
detêm um poder proporcional a seu capital simbólico, ou seja, ao reconhecimento que recebem de um grupo $^{(9)}$.

\section{RESULTADOS E DISCUSSÃO}

\section{A nova ordem social no combate à tuberculose e o HESM}

O novo Programa de Ação na Luta contra a Tuberculose no Brasil ensejou mudanças significativas nos aspectos inerentes ao tratamento dos pacientes, passando a valorizar o tratamento dispensarial. Tanto assim que, nessa nova fase, as discussões se pautavam na necessidade de investir na internação hospitalar de curta permanência, sendo utilizada a classificação por prognóstico dos pacientes e com duração média de três a seis meses voltados para educação sanitária dos internos, medicação assistida e controle dos comunicantes e egressos. Esse modelo de internação teve como objetivos conter o fenômeno da resistência bacteriana e otimizar os leitos hospitalares, reduzindo assim os gastos com a internação ${ }^{(10)}$. Sendo assim, os sanatórios realizaram reformas estruturais, de modo a atender às exigências mais recentes do controle da tuberculose, das quais se destacam a melhoria das instalações médicas e a implantação de serviços (Enfermagem, Nutrição e Readaptação) que pudessem assegurar aos pacientes as condições que favorecessem sua adaptação e tratamento(11), uma vez que muitos sanatórios não possuíam a contento essa estrutura.

O depoimento da enfermeira Raimunda da Silva Becker revela que, dentre os hospitais da Superintendência de Serviços Médicos (SUSEME) da Secretaria Geral de Saúde e Assistência do Estado da Guanabara, o HESM foi o pioneiro a implantar tais reformas, o que ocorreu em 1961. Vale ressaltar que, nesse hospital, atuavam dois médicos integrantes da Comissão Técnica da CNCT: Flávio Poppe de Figueiredo e Jesse Pandolfo Teixeira.

Para dar conta das demandas inerentes à implantação de um novo programa de ação no combate à tuberculose, houve a necessidade de rever o quadro de pessoal de enfermagem. Foi então realizado, no ano de 1960, um estudo cujos objetivos se pautaram na realização de um diagnóstico da situação com vistas à reorganização do Serviço de Enfermagem nas diversas instituições, de modo a suprir as deficiências de profissionais qualificados, no caso aqueles chamados de enfermeiros titulados, pois não possuíam diploma, os gandulas, os albergados e os estagiários ${ }^{(7)}$.

O estudo citado foi realizado pela Comissão Supervisora de Enfermagem, tendo como presidente a enfermeira Ariadne Lopes de Menezes, que era chefe da Equipe de Enfermagem dos Serviços Técnicos de Organização (SORTEC) no período de junho a novembro de 1960 . A comissão contou com a colaboração de enfermeiras dos Serviços de Saúde do Estado e da Escola de Enfermagem Rachel Haddock Lobo, atual Faculdade de Enfermagem da Universidade do Estado do Rio de Janeiro(7).

A situação descrita pela comissão demonstrou a existência de dois grupos de profissionais de enfermagem: um grupo constituído por enfermeiras diplomadas e o outro por enfermeiras tituladas. Apesar de o diploma escolar legitimar uma competência, mediante seu valor convencional, formal e juridicamente garantido, conferindo crédito ou autoridade àquele que o possui ${ }^{(12)}$, esses grupos eram concorrentes na luta por espaços de poder no interior dos espaços hospitalares.

A enfermeira Antonia de Oliveira Coelho, em seu depoimento, esclarece que no caso específico do HESM, cenário eleito para esse estudo e espaço onde seria implementada a padronização da assistência hospitalar ao paciente com tuberculose diante da nova proposta terapêutica da CNCT, as enfermeiras tituladas, ao fazerem a escala do Serviço de Enfermagem, alocavam as enfermeiras diplomadas em setores fechados, como, por exemplo, o Centro Cirúrgico, e com isso acreditavam limitar a ameaça potencial que representava a presença de uma enfermeira diplomada. No que tange à assistência direta aos doentes internos no hospital, esta era geralmente prestada pelos gandulas, albergados e estagiários.

A ausência de critérios na seleção de pessoal para trabaIhar em algumas instituições de saúde da Capital Federal concorreu para que cargos de chefias de enfermagem nesses serviços fossem ocupados por enfermeiras tituladas, portanto, sem a qualificação necessária para exercer tal função. $O$ relatório ainda evidenciou que os regulamentos, as rotinas e as técnicas de trabalho eram por demais desatualizados e tais circunstâncias eram agravadas pela pobreza dos meios de execução e pela desorganização administrativa ${ }^{(7)}$.

O excerto do depoimento de uma enfermeira lotada no HESM registra que os enfermeiros titulados não possuíam a qualificação requerida para a assistência de qualidade aos pacientes, principalmente se tratando de uma nova modalidade de assistência àqueles acometidos de tuberculose:

[...] a equipe não tinha muito conhecimento técnico, inclusive tinha uns enfermeiros que eram titulados; eles exerciam as atividades, mas não tinham o diploma de enfermeiro. Outras duas eram auxiliares de enfermagem que prestaram concurso para enfermeira do Estado; como na época não exigiram a documentação, elas fizeram e foram aprovadas, e, ao tomar posse e não portando o diploma de enfermeira, foram enquadradas como enfermeiras tituladas (JCS)

Diante desse panorama, o relatório elaborado pela Comissão Supervisora de Enfermagem, ao ser enviado ao governador do Estado da Guanabara, Carlos Lacerda, o levou a ordenar que fossem cumpridas e publicadas no Diário Oficial do Estado da Guanabara, em 15 de março de 1962, as recomendações ali contidas.

\section{O Serviço de Enfermagem do HESM: surge um contrapoder}

O HESM, vinculado ao Departamento de Tuberculose da Superintendência de Serviços Médicos (SUSEME), era subordinado à Secretaria de Saúde e Assistência do Estado 
da Guanabara. Para atender as novas demandas do tratamento da tuberculose, foi nomeado para o cargo de diretor o médico especialista em cirurgia torácica, Haroldo Voigt Meyer, figura reconhecida no campo da tisiologia.

Em relação às mudanças necessárias no Serviço de Enfermagem, foi nomeada pelo governador do Estado da Guanabara, para o cargo de chefe do Serviço de Enfermagem, a enfermeira Raimunda da Silva Becker. Convém ressaltar que essa enfermeira integrou o Grupo de Coordenação da Primeira Experiência Internacional de Quimioterapia da Tuberculose, realizada no Instituto de Tisiologia e Pneumologia, da então Universidade do Brasil, com a participação do Laboratório Central de Tuberculose do Estado da Guanabara, cujo responsável fora o Professor Hélio Fraga ${ }^{(13)}$.

Cumpre assinalar que a enfermeira Raimunda da Silva Becker era conhecida e reconhecida por expressivas autoridades médicas do campo da tisiologia em virtude de sua atuação em diferentes instituições quando tais autoridades desempenhavam cargos administrativos importantes. Em seu depoimento, reconhece a importância do prestígio conferido à enfermeira diplomada no cotidiano de suas relações profissionais com o diretor da instituição e a equipe médica em geral:

[...] a gente tinha todo prestígio [...] quando o diretor prestigia a enfermagem, os médicos seguem o modelo, foi assim no Santa Maria [Hospital Estadual Santa Maria] (RSB).

Com isso, as diferentes espécies de capital simbólico (cultural, social e científico) e sua eficiência configuram-se em poderes que definem as probabilidades de ganhos no campo $^{(9)}$.

O prestígio que a enfermeira Raimunda da Silva Becker ostentava no HESM era produto dos capitais cultural, social e científico que acumulava. O capital cultural é considerado uma grandeza que se transmite, cresce, diminui ou desaparece; uma grandeza que não é objetivável e que traz a marca dos que dela se apropriam legítima e naturalmente. Deve ser entendido como o princípio de hierarquização dominante, e também um objeto de disputa entre os gru$\operatorname{pos}^{(14)}$. O capital social pode ser traduzido como uma relação de forças entre as posições que garantem aos seus ocupantes um quantum suficiente de força social de modo que estes tenham a possibilidade de entrar nas lutas pelo monopólio do poder ${ }^{(9)}$. O capital científico, por sua vez, representa um poder institucional e institucionalizado vinculado à ocupação de posições importantes em instituições científicas, bem como ao poder de produção e de reprodução que tal ocupação representa ${ }^{(15)}$.

Outro trecho do depoimento de Raimunda da Silva Becker evidencia o reconhecimento do seu melhor trabalho como enfermeira, de modo a diferenciá-lo do que antes exista, deixando claro ser a fonte do seu capital cultural, fortalecido pela reorganização do serviço de enfermagem:

[...] eu tive uma grande chance, uma grande oportunidade de trabalho.... eu considero o trabalho que fiz no Santa
Maria [HESM] o meu melhor trabalho de enfermagem em toda profissão... não tem nada melhor [...]era um caos tão grande e ficou tão bom que eu considero o meu melhor trabalho (RSB).

Desse modo, o prestígio dos agentes depende do seu capital simbólico, isto é, do reconhecimento, institucionalizado ou não, que recebem de um grupo ou de um portavoz autorizado para falar em nome desse grupo.

Na percepção da enfermeira Raimunda da Silva Becker, o apoio do diretor da instituição foi importante para a implementação das mudanças necessárias:

[...] eu tinha carta branca completamente, tanto dos chefes de clínicas como do diretor do hospital... qualquer coisa de enfermagem que chegava, ele dizia: fale com a Raimunda [...] eles me davam toda autonomia, eles estavam vendo que a gente dava conta do negócio.

Um acontecimento de impacto substancial logo que Raimunda da Silva Becker assumiu a chefia do Serviço de Enfermagem diz respeito à redistribuição das enfermeiras diplomadas nos setores do hospital, de modo que estas ocupassem posições condizentes com sua qualificação profissional, trazendo, em consequência, alterações nas rotinas de trabalho. A percepção dessas mudanças é assim descrita por uma antiga enfermeira:

[...] eram constituídas de atividades pertinentes ao cargo de Supervisão de Enfermagem, entre elas os registros no Livro de Ocorrências, visita aos postos de enfermagem, visita aos pacientes, principalmente aos mais graves, além de orientar e acompanhar o desenvolvimento da equipe de plantão (JCS).

É pertinente colocar em relevo que tais mudanças não se processaram sem resistências da equipe médica. Raimunda da Silva Becker percebeu que alguns médicos não realizavam a visita médica aos pacientes com regularidade, limitando-se a repetir suas prescrições anteriores, e que era frequente a alta aos pacientes por indisciplina. Essa medida punitiva tinha impacto significativo no controle da tuberculose, pois implicava a dificuldade, ou mesmo a impossibilidade, de reinternação dos pacientes em outros hospitais da rede pública para o tratamento da tuberculose.

Tais situações não se coadunavam com o novo modelo de assistência, e, diante disso, a chefe de enfermagem informava à direção do hospital que a apoiava integralmente, inclusive com advertência aos médicos que não cumpriam as determinações preconizadas pela nova proposta para o tratamento dos doentes de tuberculose.

A posição dominante por parte dos médicos no campo da tisiologia à época fazia com que adotassem estratégias conservadoras, no sentido de manter a estrutura da assistência médica desenvolvida até aquele momento no HESM. O fato era motivo de intensos embates entre a chefia do Serviço de Enfermagem e alguns médicos tisiologistas daquele hospital. 
A incorporação do discurso oficial era favorecida pela autoridade dos homens, ao qual é atribuída uma distinção natural que tem suas raízes no cotidiano das relações familiares, pois a divisão sexual do trabalho é, em grande parte, consequência da divisão de tarefas domésticas estabelecida para a organização familiar ${ }^{16)}$. Assim, as enfermeiras, também na condição de funcionárias do Estado, tendiam a reproduzir o mesmo discurso, e, quando não acontecia dessa maneira, aumentavam os episódios de conflitos no interior do HESM.

Vale ressaltar que a aliança entre Raimunda da Silva Becker e o diretor da instituição, ao tempo em que possibilitava o respaldo político necessário à implementação das mudanças necessárias no Serviço de Enfermagem daquele hospital, também ratificava as diferenças sociais, mediante o reconhecimento da necessidade de tal aliança com a figura que ocupava o cargo mais importante da instituição. A esse respeito, a enfermeira Raimunda da Silva Becker assim se pronunciou:

[...] a aceitação da enfermeira diplomada dentro da hierarquia funcional foi um verdadeiro desafio que se consagrou com o entrosamento perfeito dos três dirigentes do hospital, quais sejam: diretor, chefia de enfermagem e administrador (RSB).

Além da necessidade de redistribuir as enfermeiras pelos diversos setores do hospital, a chefe do serviço identificou que havia a necessidade de qualificar o pessoal de enfermagem para as inúmeras atividades por ela consideradas prioritárias:

[...] a educação sanitária, implementar a medicação assistida, centralizar a administração da estreptomicina, adequar a escala de serviço da enfermagem, disponibilizar in- formação à família do paciente e suspensão das atividades de enfermagem durante todo o período da visita, com a finalidade de melhor atender a demanda dos familiares (RSB).

Na avaliação de Raimunda da Silva Becker, para que esses pontos prioritários fossem desenvolvidos com a adequada participação da equipe de enfermagem, seria necessário criar um programa de treinamento envolvendo toda equipe de enfermagem, sobretudo os auxiliares e técnicos de enfermagem, por representarem o maior contingente profissional naquele serviço, pois caberia à equipe de enfermagem a educação sanitária aos pacientes e seus familiares (AOC). Além disso, a dirigente de enfermagem naquela instituição criaria a oportunidade para conhecer melhor os aspectos individuais dos integrantes da equipe de enfermagem; fato importante se considerarmos que o comportamento dos membros de um grupo indica as ações/ estratégias pertinentes para lidar com estes ${ }^{(17) .}$

Assim, Raimunda da Silva Becker, à frente do Serviço de Enfermagem do HESM, pôde colaborar sobremaneira com o sucesso do trabalho naquele hospital. Tanto assim que, 18 meses após a implantação do novo Programa de Ação na Luta contra a Tuberculose, os resultados satisfatórios puderam ser comprovados, ou seja, houve melhora em quase todos os índices referentes à recuperação e à recaída dos doentes em tratamento naquele hospital, conforme evidenciado no relatório publicado na Revista Nacional de Tuberculose, em 1965, no qual constavam como autores algumas autoridades do campo científico e da tuberculose no país, dentre os quais a própria Raimunda da Silva Becker $^{(18)}$. Alguns indicadores referentes à implantação do novo Programa de Ação na Luta contra a Tuberculose serão expostos nas tabelas a seguir:

Tabela 1 - Índices Relativos ao Trabalho Técnico no HESM - Rio de Janeiro - 1964 a 30 de junho de 1965

\begin{tabular}{|c|c|c|c|c|c|c|c|}
\hline \multicolumn{2}{|c|}{$\begin{array}{c}\text { Tempo Médio de } \\
\text { Permanência do Doente } \\
\text { no Leito (em dias) }\end{array}$} & \multicolumn{2}{|c|}{$\begin{array}{l}\text { Altas de Iniciativa } \\
\text { Médica nos Casos de } \\
\text { TP }(\%)\end{array}$} & \multicolumn{2}{|c|}{$\begin{array}{l}\text { Casos de TP com } \\
\text { Alta, ainda } \\
\text { Bacilíferos (\%) }\end{array}$} & \multicolumn{2}{|c|}{$\begin{array}{l}\text { Resultados Favoráveis } \\
\text { ao Tratamento em } \\
\text { Doentes VT + PS } \\
\text { Bacilíferos com } \\
\text { Mínimo de } 90 \text { dias } \\
\text { de Tratamento }(\%)\end{array}$} \\
\hline $\begin{array}{l}\text { No ano } \\
\text { de } 1964\end{array}$ & $\begin{array}{c}01 / 01 / 1964 \\
\text { a } \\
30 / 06 / 1965\end{array}$ & $\begin{array}{l}\text { No ano } \\
\text { de } 1964\end{array}$ & $\begin{array}{c}1^{\circ} \text { Semestre } \\
\text { de } 1965\end{array}$ & $\begin{array}{l}\text { No ano } \\
\text { de } 1964\end{array}$ & $\begin{array}{c}1^{\circ} \text { Semestre } \\
\text { de } 1965\end{array}$ & $\begin{array}{l}\text { No ano } \\
\text { de } 1964\end{array}$ & $\begin{array}{c}1^{\circ} \text { Semestre } \\
\text { de } 1965\end{array}$ \\
\hline 351 & 168 & 66,5 & 82,3 & 18,8 & 9,3 & 90,7 & 95,3 \\
\hline
\end{tabular}

Fonte: Revista do Serviço Nacional de Tuberculose, Rio de Janeiro, 1965.

Legendas: TP - Tuberculose Pulmonar; VT - Virgens de Tratamento; PS - Possivelmente Sensíveis.

Os dados relativos à Tabela 1 indicam que, no decorrer do período, houve uma considerável redução no tempo médio de ocupação dos leitos, além do aumento significativo no percentual de altas por iniciativa médica, traduzindo, desta forma, a melhoria na eficiência do tratamento. Os dados revelam ainda uma substancial redução da taxa referente ao percentual de alta para os pacientes que não obtiveram a conversão bacteriológica do exame de escarro e um aumento nos resultados favoráveis quanto ao tratamento dos doentes sensíveis às drogas standard no HESM.

De acordo com os autores, esses índices, considerados favoráveis, permitiram classificar, à época, esse hospital como uma instituição para doente portador de tuberculose com bom rendimento. 
Podemos perceber que os doentes que davam continuidade ao tratamento no dispensário sob a responsabilidade técnico-administrativa do hospital também apresentaram indicadores positivos importantes, como os observados na Tabela 2.

Tabela 2 - Evolução dos Doentes Acompanhados no Ambulatório do HESM - Rio de Janeiro - 1964 a 30 de junho de 1965

\begin{tabular}{lccc}
\hline Movimento Externo & Inscritos & Abandonam & $\mathbf{( \% )}$ \\
\hline $\begin{array}{l}\text { Casos de TP em } \\
\text { tratamento ou } \\
\text { controle }\end{array}$ & 520 & 64 & 12,3 \\
$\begin{array}{l}\text { Doentes VT + PS } \\
\text { Doentes C1 }\end{array}$ & 381 & 46 & 12,0 \\
\hline
\end{tabular}

Fonte: Revista do Serviço Nacional de Tuberculose, Rio de Janeiro, 1965. Legenda: VT - Virgens de Tratamento; PS - Possivelmente Sensíveis; C1 Crônicos Tipo 1.

Os dados apresentados na Tabela 2 revelam que o índice de abandono de tratamento, considerando os doentes VT (Virgens de Tratamento), os PS (Possivelmente Sensíveis) e os Crônicos Tipo 1 (C1), era de aproximadamente $12 \%$. Esse índice era considerado baixo quando comparado a outros dispensários do Estado, à época.

Esses resultados alcançados também eram resultantes da eficiência da educação sanitária, realizada pelas enfermeiras durante o período de internação hospitalar, fase que precedia o tratamento dispensarial|(18). Um indicador importante de ser analisado refere-se às recaídas tanto bacteriológicas quanto radiológicas, como reflexo das medidas implantadas no hospital. Esses dados podem ser constatados na Tabela 3.

Tabela 3 - Recaídas bacteriológicas ou radiológicas em doentes inscritos no dispensário do HESM - Rio de Janeiro - 1964 a 30 de junho de 1965

\begin{tabular}{|c|c|c|c|c|c|}
\hline \multirow{3}{*}{ Especificação } & \multirow{3}{*}{$\begin{array}{l}\text { Total de } \\
\text { Inscritos }\end{array}$} & \multicolumn{4}{|c|}{ Recaídas } \\
\hline & & \multicolumn{2}{|c|}{ Bacteriológica } & \multicolumn{2}{|c|}{ Radiológica } \\
\hline & & $\mathbf{F i}$ & $\mathrm{Fi} \%$ & $\mathbf{F i}$ & $\mathrm{Fi} \%$ \\
\hline $\begin{array}{l}\text { Doentes } \\
\text { VT ou PS }\end{array}$ & 381 & 3 & 0,7 & - & - \\
\hline Doentes C1 & 266 & 6 & 4,5 & 2 & 1,5 \\
\hline
\end{tabular}

Fonte: Revista do Serviço Nacional de Tuberculose, Rio de Janeiro, 1965 Legenda: VT - Virgens de Tratamento; PS - Possivelmente Sensíveis; C1 Crônicos Tipo 1.

Os dados expressos na Tabela 3 indicam que o número de pacientes que apresentaram recaídas era reduzido, quando comparado com o total de inscritos no dispensário dessa instituição hospitalar, e que desses a incidência de recaídas eram maiores nos pacientes crônicos, em relação aos sensíveis às drogas standard. Mostram ainda que, nos pacientes crônicos, a recaída era tanto bacteriológica como radiológica; já os pacientes VT e PS apresentavam apenas recaída do tipo bacteriológica. Esses achados demonstram o impacto das medidas adotadas, para as quais a participação da equipe de enfermagem, sob a liderança da enfermeira Raimunda da Silva Becker como chefe do Serviço de Enfermagem, foi fundamental.

Os resultados possibilitaram ampliar a visibilidade do grupo de enfermeiras diplomadas, sobretudo a imagem de Raimunda da Silva Becker; tanto que, no ano seguinte à sua nomeação, em 1965, foi convidada a participar de um grupo de trabalho, que tinha como objetivos: propor medidas e técnicas de enfermagem com vistas a padronizar a administração e o controle da medicação para doentes com tuberculose, e elaborar recomendações para o cuidado de enfermagem aos pacientes internados, desde a admissão até a alta hospitalar, conforme observado na sua ficha funcional, identificada como: Ordem de Serviço P SUA/ № 193.

Esse grupo foi criado por determinação do Diretor do Departamento de Serviços Assistenciais da SUSEME em 16 de junho de 1965. Era composto por um presidente, o Dr. José Galbo, e mais duas chefes de Serviços de Enfermagem, a do Hospital Estadual São Sebastião e a do Hospital Estadual Clemente Ferreira, conforme constatado em sua ficha funcional, disponível no arquivo médico do HESM.

Em 1966, ainda como repercussão do trabalho realizado, Raimunda da Silva Becker recebeu e aceitou o convite do ilustre professor Hélio Fraga para chefiar o Setor de Enfermagem da CNCT, em sucessão à enfermeira Adalgisa Matos, supervisora da Fundação Serviço Especial de Saúde Pública ${ }^{(5)}$.

Cabe ressaltar que o Setor de Enfermagem da CNCT havia se configurado como um órgão consultivo da direção do Serviço Nacional de Tuberculose, o qual reunia peritos em assuntos de enfermagem com o objetivo de elaborar programas e normas de trabalho a serem adotados pelos serviços de saúde sob a orientação e supervisão da $\mathrm{CNCT}^{(5)}$.

\section{CONCLUSÕES}

As mudanças no tratamento da tuberculose, no período de 1961 a 1966, demandaram a necessidade de profissionais de enfermagem qualificados e atualizados para assistir os doentes nas diversas instituições de saúde. No âmbito do HESM, a atualização do habitus profissional da equipe de enfermagem se deu sob a liderança da enfermeira Raimunda da Silva Becker, cujo capital simbólico Ihe conferia poder e prestígio para enunciar o discurso legítimo sobre as questões relativas à assistência de enfermagem, em consonância com o novo paradigma no tratamento da tuberculose.

É notória nos depoimentos a identificação das resistências por parte dos médicos, das alianças e das relações de poder experimentadas pela chefe do serviço de enfermagem na consecução de seus objetivos, pois foi preciso estabelecer alianças sólidas com personagens importantes daquele hospital, tais como diretor e administrador. Tais ali- 
anças se configuraram como estratégias que refletiram a luta pelo monopólio legítimo por parte de uma enfermeira prestigiada no campo da tisiologia que utilizou seu capital simbólico (cultural, social e científico) como moeda de troca na luta pela reconfiguração do Serviço de Enfermagem naquele hospital.

Essa enfermeira, com sua ampla experiência na administração de enfermagem, percebeu que o êxito na implantação da nova proposta política no combate à tuberculose dependia diretamente das equipes de trabalho que compunham o quadro de pessoal do HESM, pois o comportamento dos membros de um grupo indica as ações/estraté-

\section{REFERÊNCIAS}

1. Renzo A. Situação epidemiológica da tuberculose no Distrito Federal. Rev Serv Nac Tuberc. 1946;2(7):281.

2. Bertolli Filho C. História social da tuberculose e do tuberculoso: 1900-1950. Rio de Janeiro: FIOCRUZ; 2001.

3. Nascimento DR. Fundação Ataulfo de Paiva: (Liga Brasileira Contra Tuberculose) um século de luta. Rio de Janeiro: QUADRATIM; 2002.

4. Barreira IA. A enfermeira Ananéri no 'país do futuro': a aventura na luta contra a tuberculose [tese]. Rio de Janeiro: Escola de Enfermagem Anna Nery, Universidade Federal do Rio de Janeiro; 1992.

5. Villas Boas A. O problema da tuberculose no Brasil. Rev Serv Nac Tuberc. 1962;6(21):35.

6. Garcia Filho. Novos rumos na luta contra a tuberculose. Rev Serv Nac Tuberc. 1960;4(14):115.

7. Menezes AL. Levantamento de necessidades de Enfermagem. Rev Med Estado Guanabara. 1962;29(3):130.

8. Minayo MCS. O desafio do conhecimento: pesquisa qualitativa em saúde. Rio de Janeiro: Hucitec; 1996.

9. Bourdieu P. A economia das trocas lingüísticas: o que falar quer dizer. São Paulo: EDUSP; 1998.

10. Figueiredo FP. Avaliação dos resultados do tratamento da tuberculose pulmonar. Rev Serv Nac Tuberc. 1958;2(4):191. gias pertinentes. Por isso, a interação com os integrantes dos diferentes grupos (médico, enfermagem, administrativo) foi objeto de investimento da chefe de enfermagem daquele hospital.

Assim, concluiu-se que a atuação de Raimunda da Silva Becker como chefe do Serviço de Enfermagem no HESM, ao tempo em que possibilitou a implantação do novo Programa de Ação na Luta contra a Tuberculose naquele hospital, contribuiu para demarcar o espaço e a importância da enfermeira diplomada na assistência aos acometidos de tuberculose, tanto nos aspectos da prevenção quanto da cura no cenário hospitalar no Estado da Guanabara.
11. Teixeira GM. O sanatório em face do estado atual da luta antituberculose. Rev Serv Nac Tuberc. 1961:2(6):179-94.

12. Bourdieu P. A produção da crença. São Paulo: Zouk; 2007.

13. Becker RS. Participação da Enfermeira nas investigações de quimioterapia da tuberculose: estudo de investigação de quimioterapia do Instituto de Tisiologia e Pneumologia [tese livre-docência]. Rio de Janeiro: Escola de Enfermagem Anna Nery, Universidade Federal do Rio de Janeiro; 1976.

14. Pinto L. Pierre Bourdieu e a teoria do mundo social. Rio de Janeiro: FGV; 2007.

15. Bourdieu P. O uso social da ciência: por uma sociologia clínica do campo científico. São Paulo: UNESP; 1997.

16. Siles J, Solano C. Estructuras sociales, división sexual del trabajo y enfoques metodológicos. La estructura familiar y la función socio-sanitaria de la mujer. Invest Educ Enferm. 2007;25(1):66-73.

17. Balsanelli AP, Cunha ICKO. Liderança no contexto da Enfermagem. Rev Esc Enferm USP. 2006;40(1):117-22.

18. Figueiredo FP, Meyer H, Teixeira J, Galbo J, Neves JSF, Pantoja WP, et al. O tratamento difásico da tuberculose pulmonar como recurso para diminuir a escassez de leitos nos países em vias de desenvolvimento. Rev Serv Nac Tuberc. 1965;9 (36):257-77. 